\title{
Neurotransmissão glutamatérgica e plasticidade sináptica: aspectos mo- leculares, clínicos e filogenéticos
}

\author{
Glutamatergic neurotransmission and synaptic plasticity: molecular, \\ clinical, and phylogenetic aspects
}

Rafael N. Ruggiero', Lezio S. Bueno-Júnior², Jana B. de Ross' ${ }^{1}$, Helene A Fachim³, Fernando E. Padovan-Neto², Suélen Merlo ${ }^{1}$, Carlos J. S. Rohner ${ }^{1}$, Érika T. Ikeda ${ }^{4}$, Janaína Brusco² e Jorge E. Moreira ${ }^{5}$

\begin{abstract}
RESUMO
A comunicação entre neurônios é passível de constantes modificações, até mesmo no encéfalo adulto. Esta capacidade de circuitos neuronais fortalecerem ou enfraquecerem suas interações sinápticas específicas (fenômeno conhecido como plasticidade sináptica) pode ocorrer de acordo com as diferentes demandas ambientais, o que favorece a noção de que alterações dinâmicas na comunicação entre neurônios estão na base da flexibilidade comportamental (i.e., processos de aprendizagem e memória). Nas últimas décadas, o avanço das neurociências tem permitido uma melhor compreensão a respeito da plasticidade sináptica, especialmente a plasticidade de sinapses glutamatérgicas, cujos processos moleculares de modificação sináptica parecem estar entre os mais comuns de todo o sistema nervoso central. Boa parte desse progresso na ciência básica tem contribuído para uma meIhor compreensão acerca dos processos patológicos envolvendo as sinapses glutamatérgicas, como a doença de Alzheimer. Além disso, a crescente compreensão sobre o funcionamento da comunicação glutamatérgica tem ajudado a esclarecer como as sinapses, em geral, teriam se originado e evoluído na escala filogenética do reino animal (Metazoa). A presente revisão procura abordar aspectos clínicos da neurotransmissão glutamatérgica, porém propondo uma contextualização de tais aspectos clínicos em relação a conhecimentos básicos sobre plasticidade sináptica e evolução das sinapses.
\end{abstract}

Palavras-chave: Glutamato. Excitotoxicidade. N-Metil-D-aspartato. Plasticidade Sináptica. Neuroproteção.

\section{Introdução}

O encéfalo humano possui dezenas de bilhões de neurônios e cada um deles pode se comunicar diretamente com dezenas de milhares de outros neurônios. O funcionamento orquestrado dessas comunica- ções neuronais, denominadas sinapses, é a base de processos complexos, como movimento, percepção sensorial, aprendizado, memória e emoções. Em grande parte, a flexibilidade comportamental se deve à enorme variedade de sinapses, que mediam a comunicação intercelular por diversas maneiras. Qual teria sido a
${ }^{1}$ Mestrandos e ${ }^{2}$ Doutorandos do Programa de Pós-Graduação em Neurologia/Neurociências, Departamento de Neurociências e Ciências do Comportamento da Faculdade de Medicina de Ribeirão Preto da USP (FMRP-USP). ${ }^{3}$ Doutoranda do Programa de Pós-Graduação em Psicobiologia, Departamento de Psicologia, Faculdade de Filosofia, Ciências e Letras de Ribeirão Preto da USP. ${ }^{4}$ Graduanda do Curso de Fisioterapia da FMRP-USP. ${ }^{5}$ Departamento de Biologia Celular e Molecular e Bioagentes Patogênicos, Laboratório de Estrutura Sináptica da FMRP-USP.
Correspondência: Jorge E. Moreira, cello@fmrp.usp.br Departamento de Biologia Celular e Molecular e Bioagentes Patogênicos - FMRP/USP Avenida Bandeirantes, 3900 14049-900 - Ribeirão Preto, SP

Artigo recebido em 29/10/2010 Aprovado para publicação em 20/05/2011 
origem evolutiva de tamanha complexidade de comunicação entre células? Como são os mecanismos sinápticos que fundamentam a memória? Até que ponto toda a história filogenética das sinapses explica a suscetibilidade do encéfalo humano a doenças neurológicas?

A origem evolutiva das sinapses teria dois pontos de partida: (1) uma comunicação intercelular parácrina preexistente mediada por moléculas a serem liberadas no ambiente extracelular; e (2) a excitabilidade eletroquímica da membrana plasmática ${ }^{1}$ Se por um lado a comunicação parácrina é mais específica, temporal e espacialmente, do que a endócrina, esta é capaz de percorrer longas distâncias num organismo multicelular, por meio da corrente sanguínea mediante a liberação inespecífica de grandes quantidades de moléculas sinalizadoras (hormônios; Figura 1). Comparativamente, a comunicação sináptica é tão, ou mais, específica do que a parácrina, porém tão, ou mais, eficaz do que a secreção endócrina em comunicar pontos distantes no organismo. Para a evolução deste terceiro tipo de comunicação, foi fundamental o desenvolvimento da polaridade neuronal, com seus prolongamentos de recepção (dendritos) e emissão (axônios) de sinais. Todos esses eventos evolutivos possibilitaram que animais multicelulares com neurônios (grupo Eumetazoa) possuíssem um sistema integrado de sinalização intercelular rápida à distância. Uma vez estabelecidos os sistemas nervosos mais simples em animais similares às atuais águas-vivas e planárias, por exemplo, o aumento da complexidade dos organismos multicelulares foi acompanhado por um refinamento do controle comportamental exercido diretamente pelo sistema nervoso. Assim, enquanto animais simples respondem de maneira estereotipada aos es- tímulos ambientais, animais com sistemas nervosos mais complexos possuem maior flexibilidade comportamental (i.e., capacidade de aprendizado). ${ }^{1}$

Um dos principais resultados do desenvolvimento evolutivo das sinapses foi a concentração da maquinaria biomolecular receptiva a sinais (composta pelos receptores, proteínas cinases, o citoesqueleto associado, etc.) nos locais exatos de liberação vesicular de moléculas sinalizadoras intercelulares. Assim os pontos receptivos de um neurônio são co-localizados com os terminais pré-sinápticos, provenientes de outros neurônios. Esses pontos receptivos, espalhados ao longo dos dendritos, são conhecidos como densidade pós-sináptica (ou PSD, do inglês postsynaptic density). Tal concentração de sistemas receptivos é naturalmente sensível a ativações excessivas. No caso do encéfalo humano, a super-ativação glutamatérgica pode matar neurônios (excitotoxicidade), o que pode gerar doenças neurodegenerativas. Outra vulnerabilidade trazida pelo aumento da complexidade do sistema nervoso é representada pelas epilepsias, promovidas por redundâncias na atividade de vários circuitos neurais. $^{3}$

\section{Neurotransmissão glutamatérgica e seu potencial neurotóxico}

O glutamato (L-Glu) é o principal e mais abundante neurotransmissor excitatório do sistema nervoso central (SNC) dos mamíferos, exercendo um papel crucial em mecanismos subjacentes à plasticidade sináptica. Esses mecanismos fazem parte da base fisiológica de processos comportamentais como cognição e memória. ${ }^{4}$
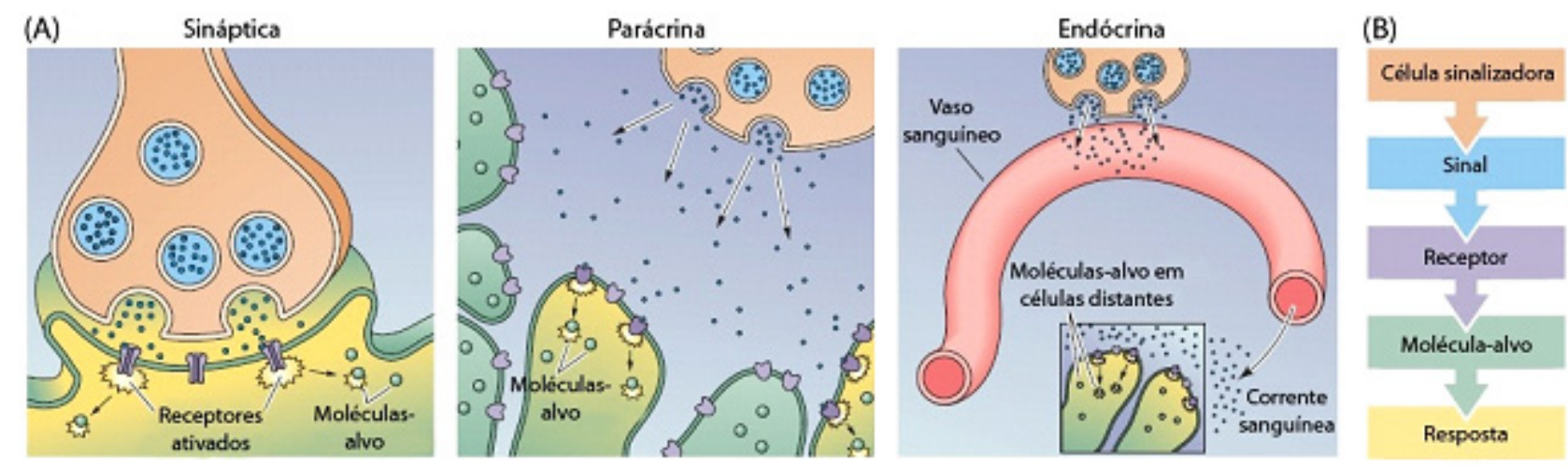

Figura 1: Mecanismos de sinalização química intercelular (adaptada e traduzida a partir da referência 2). A: principais tipos de sinalização. B: a célula emissora inicia o processo liberando moléculas sinalizadoras, que poderá se ligar a receptores específicos em células-alvo; a ativação dos receptores desencadeia cascatas de reações intracelulares que levam às respostas da célula. 
Os receptores glutamatérgicos são divididos em dois grandes grupos: os ionotrópicos (iGluRs) e os metabotrópicos (mGluRs). Os iGluRs podem ser de três tipos: N-metil-D-aspartato (NMDA), ácido-amino3-hidroxi-5-metil-isoxazol-4-propiônico (AMPA) e cainato (KA). Todos eles agregam, no mesmo complexo protéico transmembranar, sítios de recepção ao ligante e canal iônico. Assim, a neurotransmissão mediada pelos iGluRs é rápida, pois afeta diretamente o fluxo de íons (principalmente $\mathrm{Na}^{+} \mathrm{e} \mathrm{Ca}^{2+}$ ) e, consequentemente, o estado eletroquímico da membrana pós-sináptica. Existem vários subtipos de NMDA, AMPA e KA, classificados conforme as diferentes combinações das subunidades protéicas que os formam. De acordo com a combinação destas subunidades, os receptores possuem maior ou menor permeabilidade ao influxo de íons e, portanto, funcionalidades distintas. ${ }^{5}$ Por sua vez, os mGluRs são acoplados a proteínas $\mathrm{G}$ e participam dos mecanismos de resposta intracelular através da ativação de segundos mensageiros. Por esse motivo, são responsáveis pela geração de respostas pós-sinápticas mais lentas. ${ }^{6}$

Dentre todos os grupos de receptores de L-Glu o mais estudado é o NMDA, devido ao seu envolvimento com a neurotoxicidade. $\mathrm{O}$ estudo que sugeriu que o L-Glu também poderia atuar como uma neurotoxina baseou-se na observação de que injeções de L-Glu provocavam destruição das camadas mais internas da retina de camundongos. ${ }^{7}$ Essa constatação foi posteriormente replicada e expandida por Olney. ${ }^{8}$ Em 1969, propôs-se o termo "excitotoxicidade", referindo-se à neurodegeneração causada por aminoácidos excitatórios. ${ }^{9}$

Os receptores NMDA localizam-se na membrana pós-sináptica das sinapses excitatórias e exibem maior permeabilidade ao $\mathrm{Ca}^{2+}$ do que os receptores AMPA e KA, característica que lhes confere um papel mais ativo em mecanismos neurotóxicos. Os receptores NMDA são formados pela combinação de uma subunidade NR1 com um dos 4 subtipos da subunidade NR2 (NR2 $\left.{ }_{\text {A-D }}\right)$ e em alguns casos, com uma subunidade NR3. ${ }^{10}$ Quando a membrana pós-sináptica está em seu potencial de repouso, os canais NMDA encontram-se bloqueados por um íon magnésio $\left(\mathrm{Mg}^{2+}\right)$ que impede o influxo de $\mathrm{Ca}^{2+}$ para o terminal póssináptico. No entanto, sob despolarização pós-sináptica (que pode ser originada pela ativação de receptores AMPA, dentre outros), os íons $\mathrm{Mg}^{2+}$ são expulsos dos canais NMDA, o que permite o influxo de $\mathrm{Ca}^{2+} \mathrm{a}$ favor de seu gradiente de concentração. ${ }^{11}$
No citossol, o $\mathrm{Ca}^{2+}$ é um importante segundo mensageiro e influencia um grande número de funções celulares, exercendo um papel regulatório em processos de proliferação e sobrevivência celular, bem como na morte celular por necrose ou apoptose. ${ }^{12}$ Os neurônios possuem mecanismos homemostáticos especializados na manutenção intracelular tanto da localização dos íons $\mathrm{Ca}^{2+}$ quanto da concentração destes, através de uma intrincada relação entre o influxo, efluxo, captação e armazenamento no retículo endoplasmático e mitocôndria. ${ }^{13}$

$\mathrm{O}$ influxo de $\mathrm{Ca}^{2+}$ regula a excitabilidade da membrana e a intensidade da transmissão sináptica através da ativação de cascatas de sinalização intracelular dependentes deste íon. Concentrações excessivas de L-Glu na fenda sináptica resultam na superestimulação de seus receptores e entrada de $\mathrm{Ca}^{2+}$ excessiva no terminal pós-sináptico, que somadas à liberação do $\mathrm{Ca}^{2+}$ das reservas intracelulares, elevam a concentração de $\mathrm{Ca}^{2+}$ acima do limiar ativador de mecanismos regulatórios ativando os mecanismos intracelulares de excitotoxicidade que culminam na morte neuronal. ${ }^{13}$

Dentre as principais reações que podem resultar em morte neuronal, seja por necrose ou apoptose, destacam-se: alteracão da fosforilação oxidativa, diminuindo a produção de energia pelas mitocôndrias; ativação de fosfolipases, que destroem os fosfolípídios da membranana neuronal; ativação de proteases importantes para a produção de radicais livres (ROS, do inglês reactive oxygen species), responsáveis pela quebra dos fosfolipídios da membrana; ativação da enzima produtora de óxido nítrico (NOS, do inglês nitric oxide synthase) e subsequente aumento da concentração de óxido nítrico (NO), fator que media a excitotoxicidade e a produção de radicais livres. ${ }^{14}$ Esses processos podem ser frequentemente observados em situações agudas como acidentes vasculares cerebrais, hipoglicemia, hipóxia e trauma, como também na maioria das doenças neurodegenerativas, como Doença de Parkinson, Alzheimer, Huntington e Esclerose Lateral Amiotrófica, nas quais ocorre a morte celular de grupos de neurônios específicos. ${ }^{15}$

O potencial neurotóxico do L-Glu é atenuado pelo seu mecanismo de recaptação, responsável por removê-lo da fenda sináptica. Após a ligação aos seus receptores, o L-Glu é captado por transportadores de alta afinidade presentes nos astrócitos adjacentes à sinapse, evitando sua permanência no espaço extracelular. Ainda no astrócito, o L-Glu é convertido em 
glutamina pela enzima glutamina sintetase. Então, as moléculas de glutamina são liberadas para o meio extracelular e transferidas por transportadores específicos para o terminal pré-sináptico, onde são re-convertidas em glutamato pela enzima glutaminase (Figura 2). Portanto, o ciclo glutamato-glutamina é o principal mecanismo de finalização da neurotransmissão glutamatérgica, exercendo um efeito neuroprotetor. ${ }^{16}$

\section{Plasticidade sináptica e neurotrans- missão glutamatérgica}

Uma das propriedades mais fascinantes do sistema nervoso é sua plasticidade: a capacidade de a atividade neural gerada por uma experiência modificar a função de circuitos neurais e assim modificar pensamentos, sentimentos e comportamentos. Mais especificamente, a plasticidade sináptica é a capacidade de modificação na eficiência da transmissão sináptica (aumento ou diminuição da resposta pós-sináptica) pela atividade neural gerada por uma experiência. Seus efeitos podem envolver alterações no pro- cessamento de informações e na comunicação entre regiões cerebrais, regulando processos de formação de memória, abuso de drogas e estados afetivos. Podemos subdividir os fenômenos de plasticidade sináptica em duas categorias: plasticidade sináptica de curta duração e de longa duração. ${ }^{17}$ A plasticidade sináptica de curta duração ocorre quando um padrão de atividade neural gera uma alteração na transmissão sináptica por curto período de tempo (dezenas ou centenas de milissegundos) sendo possível observar inibição ou facilitação da resposta do neurônio pós-sináptico. Os mecanismos moleculares da inibição envolvem a inativação de canais de sódio e canais de cálcio dependentes de voltagem ou a depleção de vesículas sinápticas. No caso da facilitação, ocorre acúmulo de íons $\mathrm{Ca}^{2+}$ no terminal pré-sináptico, o que favorece a liberação de uma quantidade maior de neurotransmissores. Acredita-se que esses dois mecanismos de plasticidade sináptica de curta duração possuam um papel importante nas adaptações rápidas a estímulos sensoriais, mudanças transitórias em estados comportamentais e formas curtas de memória. ${ }^{18}$

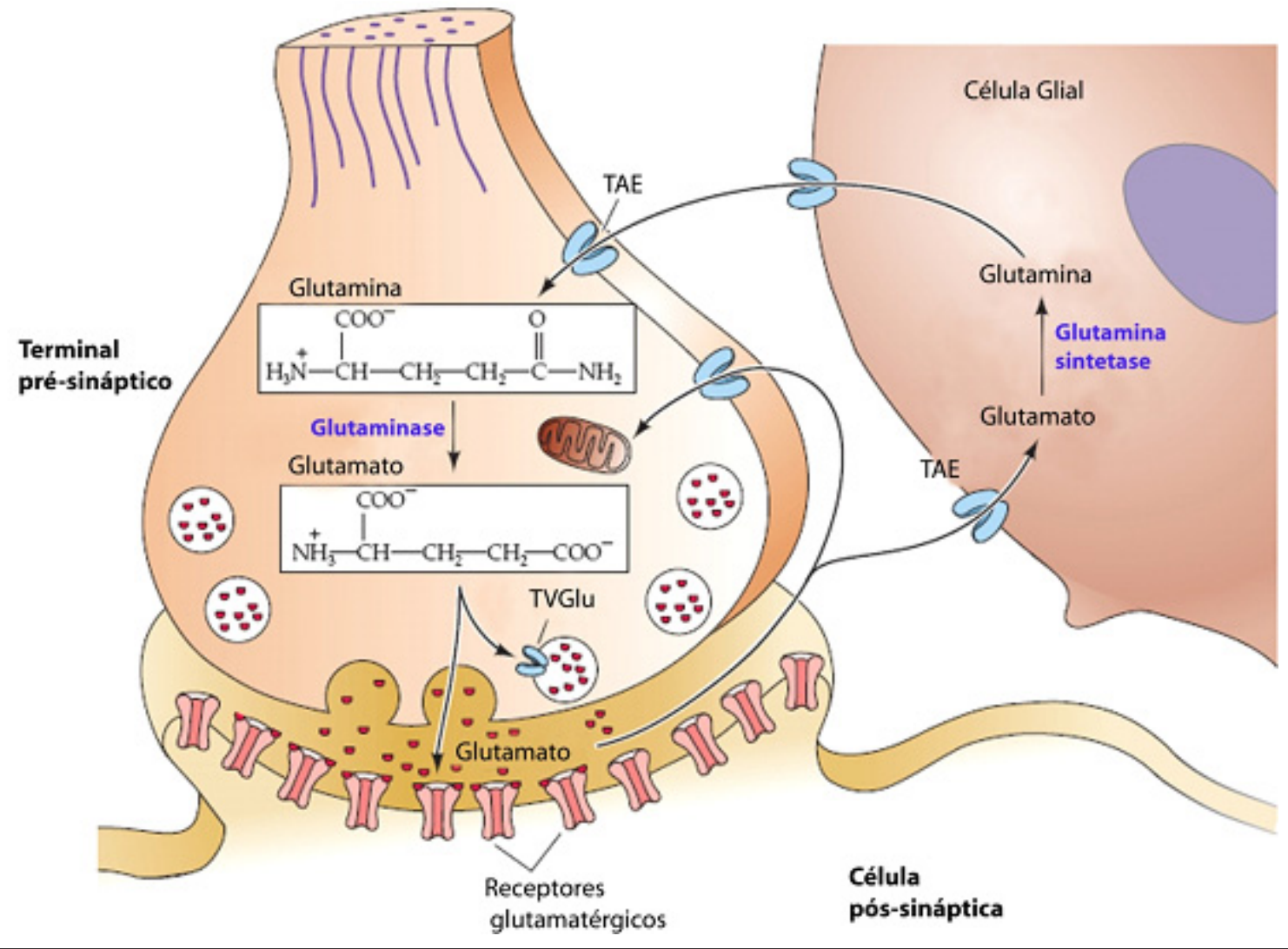

Figura 2: Síntese de glutamato e ciclo entre neurônio e célula glia (adaptada e traduzida a partir da referência 2). A ação do glutamato liberado na fenda sináptica é limitada pela recaptação através de transportadores específicos em neurônios e células glias adjacentes. No terminal pré-sináptico, a glutamina liberada por células gliais é recaptada pelos neurônios e convertida em glutamato. O glutamato é transportado para dentro das células através de transportadores de aminoácidos excitatórios (TAEs) e armazenado em vesículas por transportadores vesiculares de glutamato (TVGlu). 
A plasticidade sináptica de longa duração, por sua vez, gera alterações que duram horas ou até dias e pode ser estudada através de dois mecanismos: a potenciação de longa duração (ou LTP, do inglês longterm potentiation) e a depressão de longa duração (ou LTD, do inglês long-term depression; Figura 3a). A LTP é observada experimentalmente quando estímulos elétricos são aplicados em alta frequência sobre uma determinada população de neurônios. Isso pode provocar a potenciação sustentada dos potenciais pós-sinápticos de uma determinada região encefálica que receba projeções axonais daquela população neuronal estimulada. ${ }^{19}$ Várias propriedades básicas fazem com que a LTP constitua um modelo celular de memória. Similar à memória, a LTP pode ser gerada rapidamente e é fortalecida e prolongada por repetição. Ela também exibe cooperatividade, associatividade e especificidade. Cooperatividade diz respeito à propriedade de que a LTP pode ser induzida pela ativação coincidente de um número crítico de sinapses. Associatividade é a capacidade de potencializar uma informação neuronal fraca (mediada por um pequeno número de sinapses) quando esta é ativada em associação temporal com uma informação neuronal forte (proveniente de um grande número de sinapses ativadas), sendo esta propriedade considerada um análogo celular do condicionamento clássico Pavloviano. Finalmente, especificidade indica que a LTP só pode ser induzida em sinapses ativadas e não em sinapses adjacentes inativas. Essa característica aumenta drasticamente a capacidade de armazenamento de células individuais, já que sinapses diferentes de um mesmo neurônio podem estar codificando informações com diferentes pesos. ${ }^{20}$ a

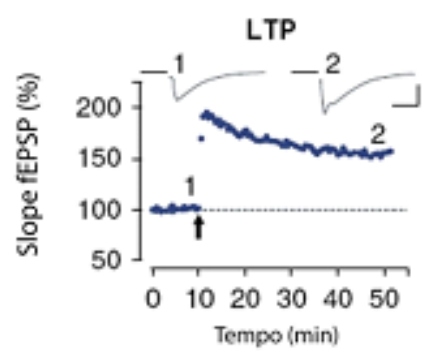

c

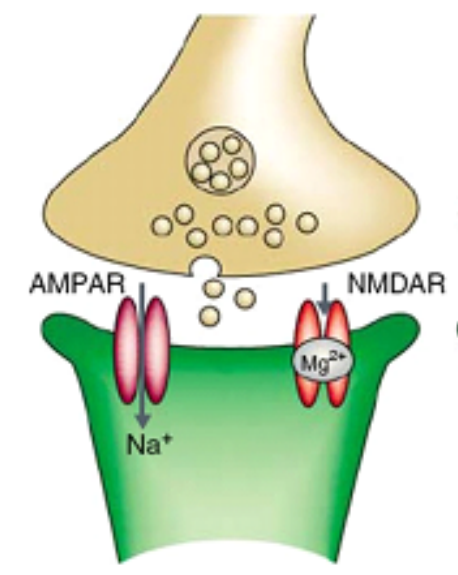

b

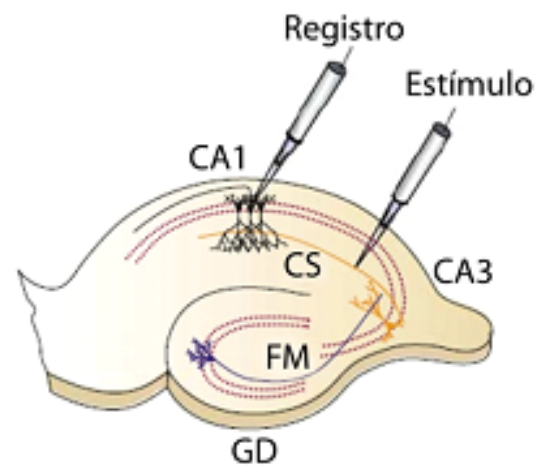

GD
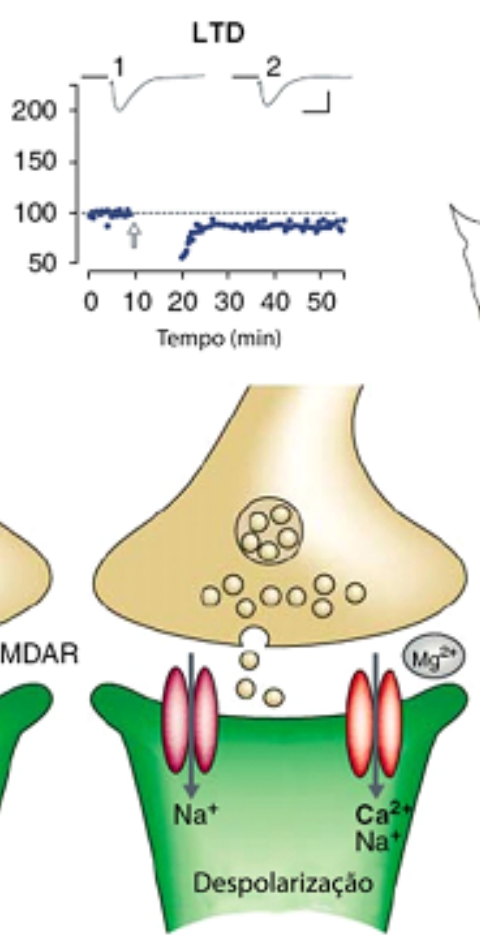

Figura 3: LTP e LTD dependente de NMDA em sinapses hipocampais da região CA1 (adaptada e traduzida a partir da referência 17). A: Experimentos ilustrando LTP e LTD na região CA1 do hipocampo. Potencialização sináptica, definida como a inclinação (taxa de despolarização) do potencial excitatório pós-sináptico de campo, ao longo do tempo. O painel à esquerda mostra a LTP induzida por estimulações de alta freqüência (100 Hz durante $1 \mathrm{~s}$; seta). O painel à direita ilustra a LTD induzida por estimulação de baixa freqüência ( $5 \mathrm{~Hz}$ a cada 3 minutos aplicada duas vezes com um intervalo de 3 minutos entre elas). B: Diagrama esquemático de um corte hipocampal de roedores, demonstrando as regiões CA1, CA3 e o giro denteado (GD). CS = colaterais de Schaffer; FM = fibras musgosas. Estão indicadas posições típicas de eletrodos para o estudo da plasticidade sináptica nas sinapses das colaterais de Schaffer em CA1. C: Modelo de transmissão sináptica em sinapses excitatórias. Durante a transmissão sináptica basal (painel à esquerda) o glutamato ligase a receptores AMPA (AMPAR) e NMDA (NMDAR). Ocorre influxo de Na+ somente através dos receptores AMPA. Após a despolarização da célula pós-sináptica (painel à direita) o $\mathrm{Mg}^{2+}$ se desprende do receptor $\mathrm{NMDA}^{2}$ permitindo o influxo de $\mathrm{Na}^{+} \mathrm{e} \mathrm{Ca}^{2+}$ no espinho dendrítico . $\mathrm{O}$ aumento na concentração de $\mathrm{Ca}^{2+}$ é necessário para o disparo de eventos que levam à plasticidade sináptica. 


\section{LTP dependente de NMDA}

A LTP que ocorre nas sinapses excitatórias da região CA1 do hipocampo é a forma de plasticidade melhor estudada, servindo de protótipo para várias outras LTPs que ocorrem no encéfalo (Figura 3b). Neste tipo de LTP, uma grande quantidade de L-Glu é liberada na fenda sináptica após uma estimulação de alta frequência. L-Glu se liga tanto a receptores do tipo AMPA quanto aos NMDA. Porém, como dito anteriormente, esses receptores estão bloqueados por magnésio quando a célula encontra-se no potencial de repouso. Entretanto, com a ativação de canais AMPA e o consequente influxo de sódio, o neurônio se despolariza e o íon magnésio se dissocia do sítio de ligação ao receptor NMDA permitindo a passagem de íons $\mathrm{Na}^{+} \mathrm{e} \mathrm{Ca}^{2+}$ pelo canal. A ativação de receptores NMDA e o aumento da concentração de $\mathrm{Ca}^{2+}$ intracelular, acima de um determinado limiar, ativam a maquinaria bioquímica responsável pela indução da LTP (Figura 3c). Portanto, para que ocorra a indução da LTP, o receptor NMDA precisa estar ativado e a célula deve estar despolarizada. Essas propriedades do receptor NMDA também explicam as propriedades básicas da LTP cooperatividade, associatividade e especificidade. ${ }^{20}$

Fortes evidências demonstram que as ativações de várias proteínas-cinases estão subjacentes a indução da LTP como a proteína-cinase II dependente de cálcio/calmodulina (CaMKII), que autofosforila após a indução de LTP. ${ }^{21} \mathrm{~A}$ inibição dessa proteína previne a indução da $\mathrm{LTP}^{22}$ enquanto o aumento de sua concentração no terminal pós-sináptico potencializa a conexão sináptica. ${ }^{23}$ Uma série de outras proteínas-cinases parece estar implicada na indução da LTP, dentre elas a $\mathrm{PKA}^{24}, \mathrm{PKC}^{25}$ e a MAPK. ${ }^{26}$

Atualmente, o consenso entre os pesquisadores é de que a indução da LTP dependente de NMDA envolve alterações no neurônio pós-sináptico, principalmente um aumento da disponibilidade de receptores AMPA na membrana celular. ${ }^{27}$ Uma grande contribuição para essa hipótese veio da descoberta das sinapses silenciosas: sinapses que possuem receptores NMDA, mas poucos receptores AMPA e, assim, exibem resposta pós-sináptica fraca ao L-Glu. ${ }^{28}$ Porém, após indução de LTP essas sinapses começam a apresentar atividade excitatória, o que é creditado à incorporação de receptores AMPA à membrana pós-sináptica. Essa hipótese foi expandida para sinapses que já contêm receptores AMPA, onde a maquinaria bioquímica envolvida na LTP poderia regular o tráfego vesicular deste receptor e aumentar sua inserção na membra-

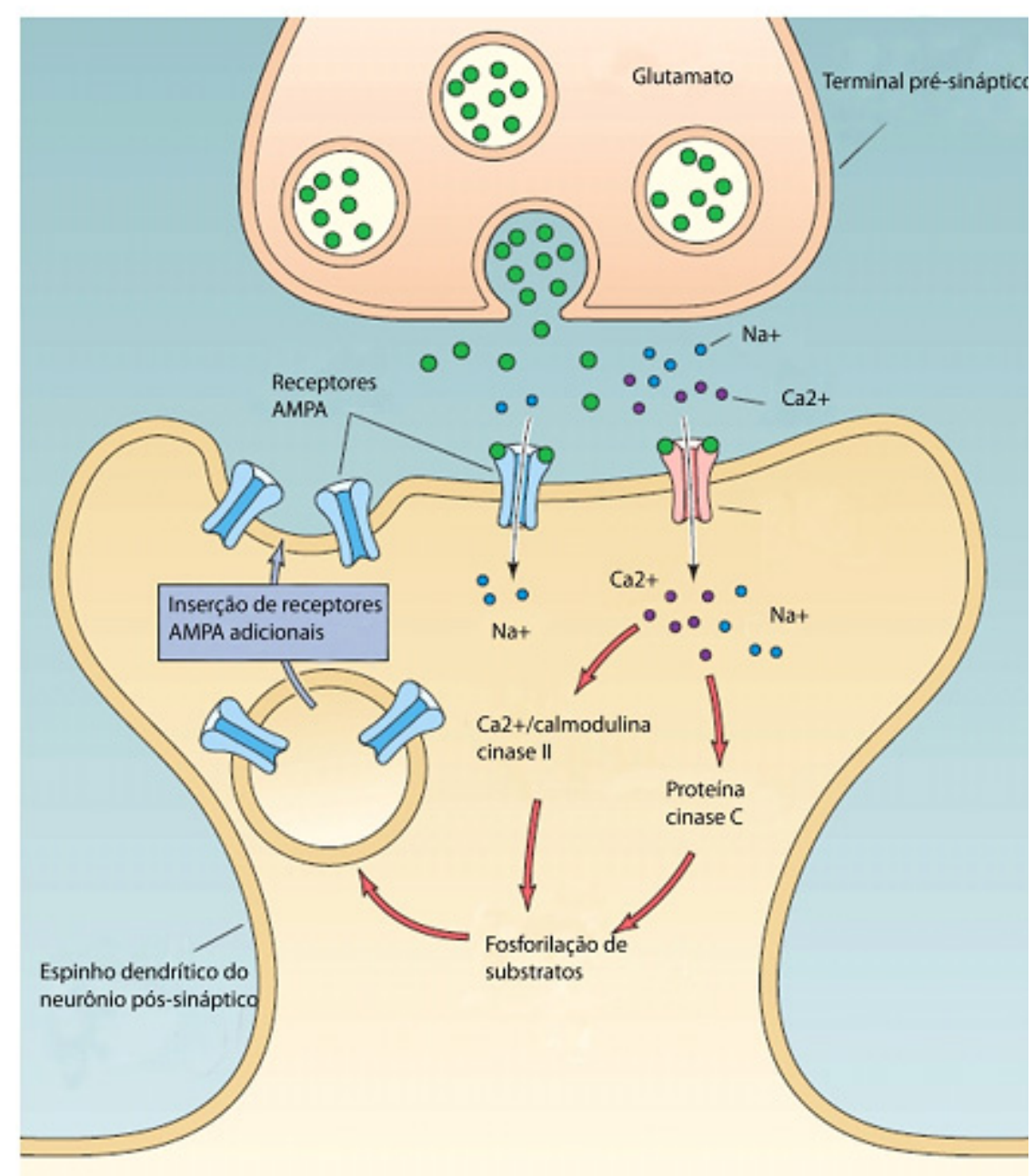

Figura 4: Mecanismos subjacentes à LTP (adaptada e traduzida a partir da referência 2). Durante a transmissão glutamatérgica, o canal de NMDA (apontar na figura) se abre somente após despolarização suficiente da célula. Os íons $\mathrm{Ca}^{2+}$ que entram na célula ativam proteínas cinases que podem atuar inserindo novos receptores AMPA no espinho pós-sináptico (dendritico? Todos os espinhos são pós-sinápticos), aumentando assim, a sensibilidade ao glutamato. 
na. Um modelo para os eventos que ocorrem durante a primeira hora de LTP envolve cascatas moleculares dependentes de cálcio, principalmente CaMKII, promovendo a fosforilação das subunidades GluR1 de receptores AMPA. Tal fosforilação resulta em um aumento da condutância de cada canal AMPA e, simultaneamente, os mesmos são expostos na fenda sináptica via exocitose ocasionando um aumento da concentração desses receptores na membrana (Figura 4). Juntos, todos esses eventos resultam em um aumento da excitabilidade pós-sináptica. ${ }^{17}$

A fase tardia da LTP (definida como a potencialização após 1-2 h depois de sua indução) depende de síntese protéica no espinho dendritico bem como de transcrição gênica no núcleo celular. ${ }^{29} \mathrm{~A}$ sinaliza- ção para essa transcrição nuclear parece depender de uma série de enzimas como PKA, CaMKs e MAPK que ativam fatores de transcrição como CREB e genes como c-Fos e Zif268. ${ }^{30}$ Esses complexos transcricionais promovem a expressão de genes requeridos para a manutenção da potencialização sináptica. Uma possibilidade para a manutenção da LTP (fase tardia) é o remodelamento estrutural das sinapses potencializadas. Diversos estudos demonstram que mudanças morfológicas acompanham a LTP (Figura 5). Essas mudanças incluem crescimento de novas espinhos dendríticos, aumento de espinhos pré existentes e suas respectivas densidades pós-sinápticas (PSDs), e a divisão de um espinho em dois terminais pós-sinápticos funcionais. ${ }^{31}$
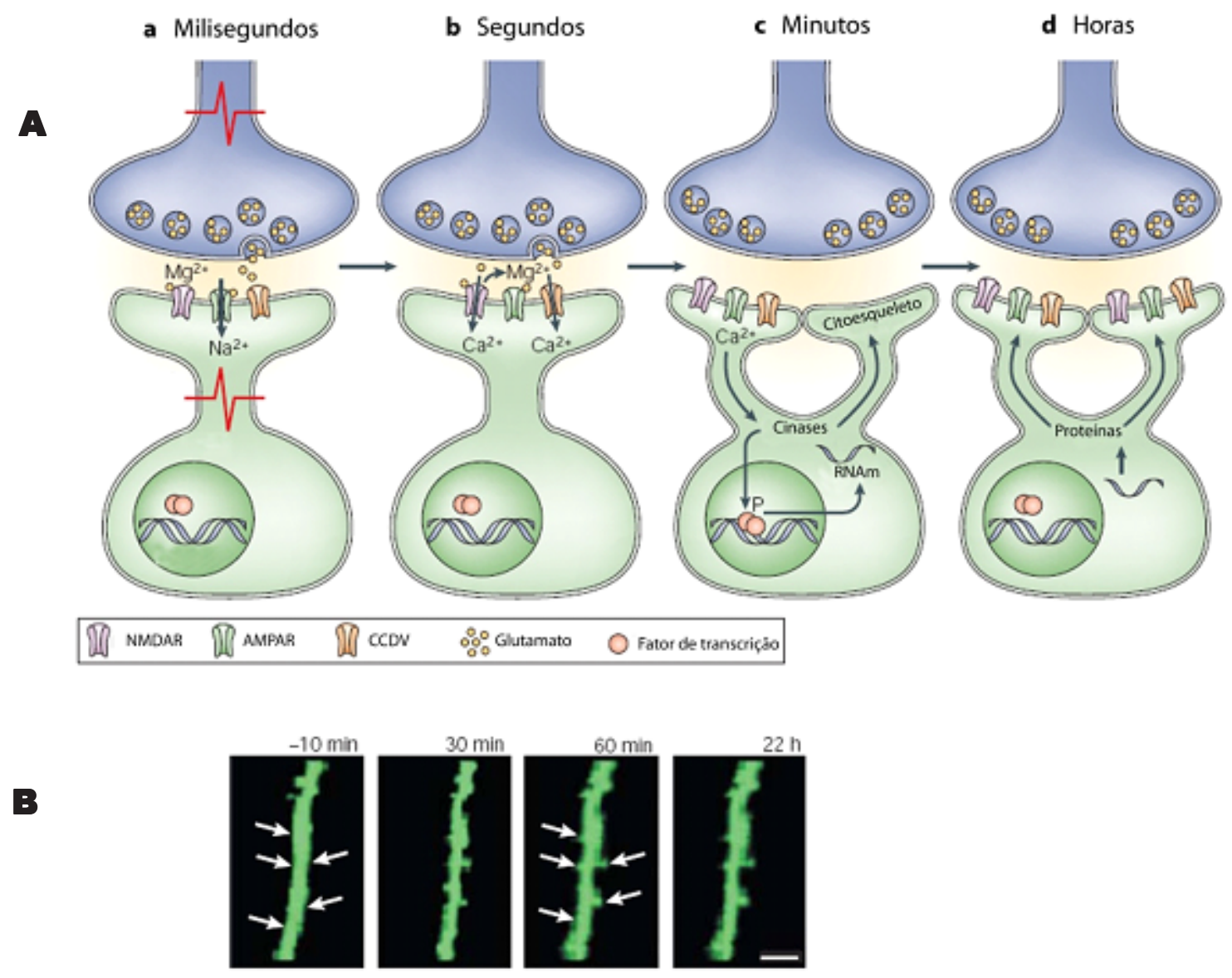

Figura 5: (A) Mecanismos envolvidos na iniciação e manutenção da plasticidade sináptica (adaptada e traduzida a partir da referência 31). (a) A liberação de glutamato de neurônios pré-sinápticos leva à ativação de receptores AMPA (AMPAR) e à despolarização do neurônio pós-sináptico. (b) A despolarização do neurônio pós-sináptico e concomitante ativação por glutamato levam à remoção do $\mathrm{Mg}^{2+}$ dos receptores NDMA (NMDAR) e ao influxo de $\mathrm{Ca}^{2+}$ no espinho dendrítico. A despolarização também ativa canais de cálcio dependentes de voltagem (CCDV), outra fonte de $\mathrm{Ca}^{2+}$ pós-sináptico. (c) $\mathrm{O}$ influxo de $\mathrm{Ca}^{2+}$ na sinapse ativa quinases que, por sua vez, modulam a atividade de seus substratos. Esses substratos contribuem para mudanças locais, como alterações morfológicas, através de regulação de proteínas do citoesqueleto ou indução da transcrição de RNA no núcleo através de fatores de transcrição. (d) RNAm levam à formação de proteínas que são capturadas pelas sinapses ativadas e contribuem para a estabilização de mudanças no espinho dendrítico. (B) a LTP pode induzir crescimento (tempo na figura relativo à indução de LTP) de novos espinhos dendríticos, indicados por setas (microscopia de dois fótons). 


\section{LTD dependente de NMDA}

Em 1992, Dudek e Bear ${ }^{32}$ demonstraram que células piramidais de CA1 quando estimuladas a baixa frequência (900 estímulos a 1Hz) apresentavam uma diminuição da resposta pós-sináptica que podia durar horas. A demonstração desse fenômeno de depressão de longa duração (LTD) mostrou que a atividade sináptica podia ser controlada de maneira bidirecional e que as memórias seriam codificadas por distribuição de "pesos sinápticos" e não somente pelo aumento da atividade sináptica (LTP). Assim como a LTP, diferentes formas de LTD podem ser encontradas no sistema nervoso. A forma mais bem estudada e prototípica é a LTD dependente de receptores NMDA.

A indução da LTD envolve a ativação de proteínas fosfatases dependentes das cascatas reguladas por $\mathrm{Ca}^{2+}$, principalmente calcineurina, proteína fosfatase 1 (PP1) e uma fosfoproteína chamada de inibidor 1 (I1). Consistentemente, foi demonstrado que a inibição dessas fosfatases reduz a LTD. ${ }^{34}$ A LTD também está associada à desfosforilação de sítios de atuação de PKA e PKC, cinases envolvidas na LTP. ${ }^{35}$ A desfosforilação da subunidade GluR1 no sitio de atuação da PKA está associado a uma diminuição da probabilidade de abertura de canais AMPA, o que pode contribuir para a indução de LTD. ${ }^{36}$

Ao contrário ao que ocorre na LTP, acredita-se que na LTD dependente de receptores NMDA ocorra endocitose de receptores AMPA diminuindo a resposta pós-sináptica. Estudos mostraram que manipulações farmacológicas da atividade neural causam internalização de receptores AMPA da membrana pós-sináptica ${ }^{37}$ e que esta endocitose é regulada por desfosforilação dependente de cálcio (Figura 6). ${ }^{38,39}$ Poucos traba- lhos foram dedicados ao estudo da manutenção da LTD, mas esta também parece envolver transcrição de proteínas e alterações morfológicas. Há evidências de que a LTD é acompanhada por um encolhimento no tamanho dos espinhos dendriticos e que isso pode ser devido à perda de receptores AMPA na membrana pós-sináptica. ${ }^{40}$ De fato, o tamanho do espinho dendrítico está intimamente relacionado ao número de receptores AMPA expostos em sua superfície. ${ }^{41}$

\section{Papel funcional da plasticidade sináptica de longa duração}

Diversos estudos demonstraram a conexão entre esses fenômenos eletrofisiológicos experimentais e a plasticidade sináptica dependente de experiência (i.e. interação com o ambiente). Os trabalhos concentraram seus esforços na relação entre a LTP hipo-

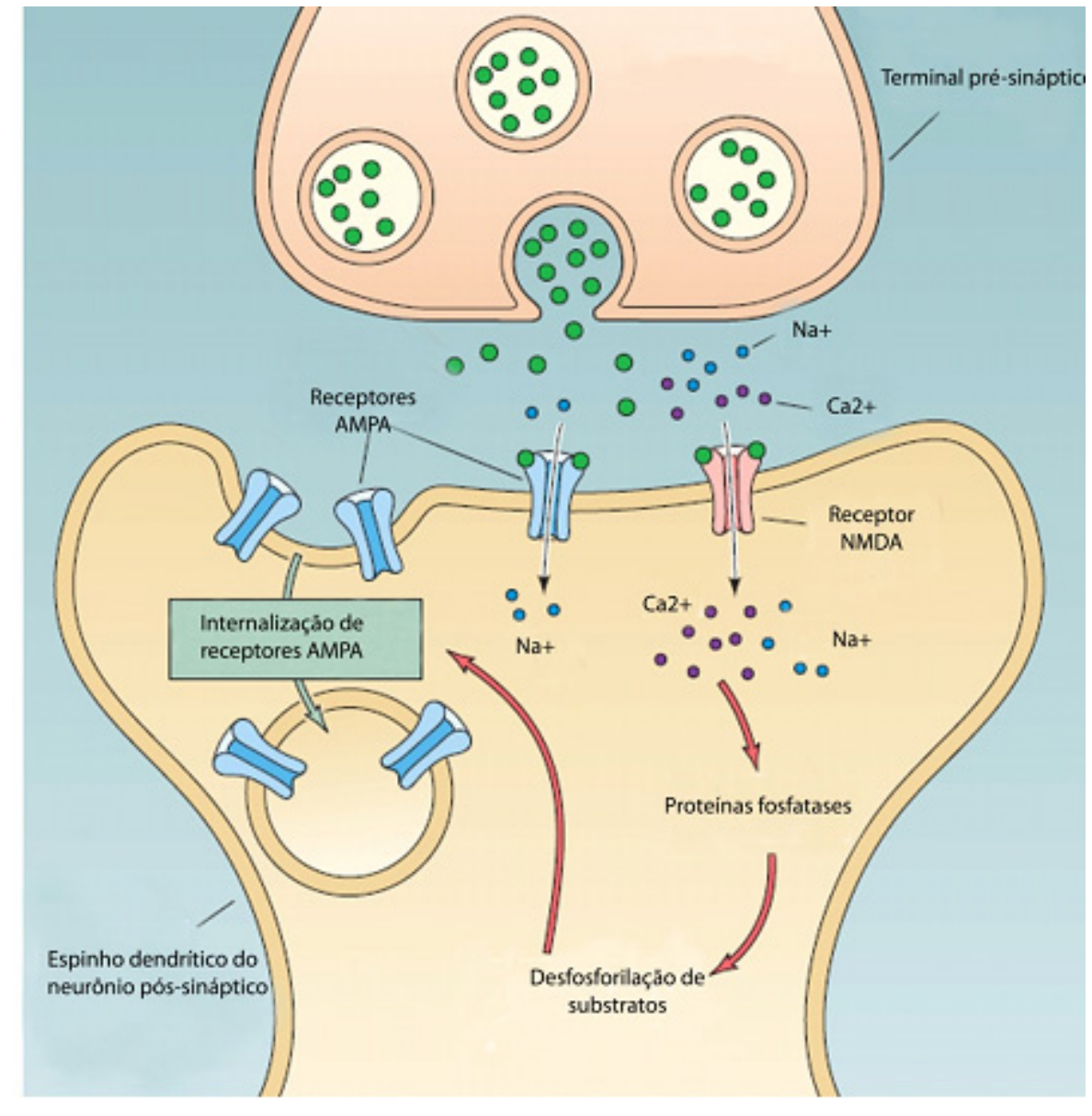

Figura 6: Mecanismos subjacentes à LTD (adaptada e traduzida a partir da referência 2). Um aumento pequeno na concentração de $\mathrm{Ca}^{2+}$ intracelular ativa proteínas fosfatases que podem causam internalização de receptores AMPA no espinho pós-sináptico, diminuindo assim, a sensibilidade ao glutamato. 
campal e a aprendizagem. Em estudos com modelos animais, a injeção de antagonistas de receptores NMDA, bem como a utilização de camundongos knockouts para o gene que expressa uma subunidade deste mesmo receptor, demonstrou-se deficiências na LTP e no aprendizado em tarefas espaciais. ${ }^{42}$ Por outro lado, camundongos que hiper-expressam a subunidade NR2B para aumentar a função dos receptores NMDA apresentam potenciação da LTP e um incremento da aprendizagem espacial. ${ }^{43}$ Recentemente, dois artigos reforçaram a idéia de que a LTP poderia ser um mecanismo celular de memória. O primeiro mostrou que durante uma tarefa de aprendizado comportamental a LTP pôde ser registrada in vivo em células hipocampais, indicando que padrões de atividade durante uma tarefa de aprendizado são suficientes para induzir LTP. ${ }^{44}$ Yao e colaboradores mostraram que a injeção de inibidores da enzima PKM $\zeta$ aboliu tanto a manutenção da LTP quanto o armazenamento de um aprendizado espacial sugerindo que a manutenção (fase tardia) da LTP é requerida para se manter a memória. ${ }^{45}$

Outros estudos concentraram-se na plasticidade sináptica na amígdala - estrutura envolvida no processamento emocional e fundamental no condicionamento pelo medo. Tsvetok e colaboradores ${ }^{46}$ demonstraram que o condicionamento pelo medo potencializa a transmissão sináptica nessa via, enquanto a expressão modificada de um peptídeo de GluR1 que bloqueia a incorporação de novos receptores AMPA aboliu a aquisição desse tipo de memória associativa. ${ }^{47}$ Atualmente acredita-se que extinção do medo é uma nova forma de aprendizado e não o esquecimento de uma memória aprendida. De acordo com isso, a administração de d-ciclosterina na amígdala, um agonista parcial de NMDA, aumenta a aprendizagem responsável pela extinção do medo. ${ }^{48}$

Além do acima citado, diversos estudos vem focando sua atenção na plasticidade sináptica subjacente a diversos eventos patológicos e não patológicos do funcionamento do encéfalo, como exemplo: a plasticidade sináptica é implicada no comportamento relacionado ao vício de drogas e a circuitos de recompensa dopaminérgicos ${ }^{49,50}$; no desenvolvimento do sistema nervoso sensorial ${ }^{51,52}$ e em doenças neurodegenerativas como a Doença de Parkinson. ${ }^{53}$ A plasticidade sináptica no córtex pré-frontal tem implicações no funcionamento do sono, na consolidação de memórias de longo prazo e no surgimento de transtornos psiquiátricas associados às epilepsias. ${ }^{54}$

\section{Drogas que previnem a excitotoxi- cidade}

O conhecimento das características moleculares dos receptores L-Glu provê recursos para o estudo dos mecanismos envolvidos nas doenças neurodegenerativas (estresse oxidativo, produção de radicais livres e excitotoxicidade). Terapias para o tratamento dessas doenças têm objetivado o bloqueio dos receptores de L-Glu com moléculas antagonistas. O mecanismo de ação dessas drogas seria o de inibir os efeitos dos aminoácidos excitatórios e o acumúlo de $\mathrm{Ca}^{2+}$ intracelular. ${ }^{55}$

Acredita-se que todos os subtipos de receptores glutamatérgicos estejam envolvidos de alguma maneira na mediação da excitotoxicidade, através de mecanismos dependentes de $\mathrm{Ca}^{2+} .{ }^{56}$ No entanto, os iGluRs continuam reconhecidos por exercer o papel fundamental, já que existe uma estreita relação entre o influxo de $\mathrm{Ca}^{2+}$ e a injúria neuronal, ambos em resposta à ativação excessiva desse tipo de receptores glutamatérgicos. ${ }^{57}$

Experimentos com antagonistas de receptores glutamatérgicos foram pioneiros em demonstrar que o bloqueio da excitotoxicidade exerce efeito neuroprotetor, tanto in vitro ${ }^{58}$ quanto in vivo. ${ }^{59,60}$ Portanto, o foco das pesquisas iniciais foi o bloqueio do excesso de $\mathrm{Ca}^{2+}$ intracelular resultante da super-estimulação glutamatérgica mediante antagonistas glutamatérgicos. Entretanto, foi constatado que o bloqueio dos receptores glutamatérgicos influenciava a função cerebral normal e produzia efeitos colaterais. ${ }^{61}$

Dentre os antagonistas de NMDA estão o MK-801, a memantina e a gaciclidina (GK-11). O MK-801 é um antagonista não-competitivo seletivo dos receptores de NMDA e possui efeito anticonvulsivante quatro vezes maior quando comparado aos benzodiazepínicos. Entretanto, foi demonstrado por Olney $^{62}$ e Fix ${ }^{63}$ que doses efetivas desse antagonista causam lesões em regiões corticolímbicas, provavelmente devido à superestimulação da via colinérgica, uma consequência da desinibição de múltiplos caminhos excitatórios convergentes. ${ }^{64}$ A memantina, por sua vez, é um antagonista não-competitivo de NMDA e seu efeito neuroprotetor é amplamente aceito por ser uma droga aprovada pela FDA desde $2003 .{ }^{65}$ É utilizada na tentativa de reduzir a deterioração cognitiva e a perda das funções diárias em pacientes com Doença de Alzheimer em estágios de moderado a severo. Finalmente, o GK-11 é um antagonista não-se- 
letivo dos receptores de NMDA que se destaca por possuir menor afinidade por esses receptores (dez vezes menor comparado ao MK-801) e, portanto, menos neurotóxico. ${ }^{66,67}$ Por esse motivo, é um dos candidatos mais promissores à neuroproteção contra a excitotoxicidade.

Outra droga que possui propriedades neuroprotetoras é o dantrolene sódico, um antagonista dos receptores de rianodina. Esses receptores localizam-se na membrana do retículo endoplasmático e são responsáveis pelo controle da saída de $\mathrm{Ca}^{2+}$. Por isso, o bloqueio da liberação de $\mathrm{Ca}^{2+}$ pelo retículo pode prevenir reações secundárias desencadeadas pelo acúmulo de $\mathrm{Ca}^{2+}$ intracelular. ${ }^{68}$

Alguns anestésicos, incluindo os voláteis, como o halotano, sevoflurano e isoflurano; os barbitúricos, como tiopental e pentobarbital; e o propofol, apresentam efeito neuroprotetor em modelos de lesão isquêmica aguda, porém não são capazes de manter esse efeito após muitas horas ou dias. O efeito neuroprotetor desses anestésicos é atribuído à potencialização da neurotransmissão GABAérgica, mediação dos receptores do tipo NMDA e AMPA e consequente redução do influxo de $\mathrm{Ca}^{2+}{ }^{29}$ Os anestésicos possuem características neuroprotetoras somente após os primeiros estágios das lesões isquêmicas, porém esse efeito não é mantido nos estágios mais avançados.

Existem várias drogas com mecanismos distintos que atuam na tentativa de bloquear e/ou prevenir os efeitos da excitotoxicidade glutamatérgica, no entanto, até o momento nenhuma droga ou esquema politerapêutico conseguiu bloquear a morte de neurônios decorrente destes estímulos. Nesse sentido, fazse necessária a busca de novos compostos a serem utilizados como ferramentas para o estudo dos processos patológicos e para prospecção de novos agentes terapêuticos co-adjuvantes.

\section{Origem e evoluçăo das sinapses com ênfase em receptores glutama- térglcos}

A análise filogenética procura elucidar as relações de parentesco entre todas as espécies, desde as existentes hoje em dia até aquelas que foram extintas ao longo da história geológica. Tais relações são representadas graficamente por cladogramas, semelhantes a árvores genealógicas, como o mostrado na Figura 7. O cladograma da Figura 7 diz respeito a sinapses, especificamente, omitindo enormes ramificações de grupos animais e seus subgrupos. Portanto, trata-se de um cladograma simplificado, mostrando somente relações de parentesco entre grupos panoramicamente delimitados. Ainda assim, o cladograma da Figura 7 é útil para indicar as principais etapas evolutivas das sinapses ao longo do tempo geológico.

\section{Análise filogenética da densidade pós-sináp- tica}

Segundo a revisão de Ryan e Grant $^{70}$, trabalhos de análise filogenética da PSD têm utilizado a estratégia de comparar as principais proteínas das sinapses de vertebrados (tais como os receptores glutamatérgicos, GABAérgicos, colinérgicos, as proteínas G associadas a alguns desses receptores, etc.) com proteínas homólogas em duas categorias de seres vivos: (1) organismos protossinápticos, representados pelos eucariotos unicelulares e animais sem sistema nervoso (poríferos) e (2) animais não-bilaterais com sistema nervoso simples e difuso (cnidários). A meta da comparação entre proteínas sinápticas de vertebrados com eventuais proteínas homólogas da primeira categoria é a identificação de proteínas que já existiam antes do surgimento das primeiras sinapses. Por outro lado, o objetivo da comparação entre as mesmas proteínas de vertebrados com proteínas homólogas da segunda categoria é o de esclarecer a composição protéica das sinapses mais primitivas do reino animal, visando-se à compreensão de aspectos evolutivos do sistema nervoso.

\section{Organismos protossinápticos}

Por meio da investigação comparativa, supõese que as proteínas mais antigas que fazem parte das sinapses de vertebrados já estavam presentes no ancestral comum de todos os eucariotos. Afinal, leveduras (do grupo Fungi) e mamíferos compartilham cerca de $25 \%$ dos genes que, em mamíferos, codificam proteínas importantes para as sinapses. Por exemplo, a proteína cinase $\mathrm{C}$ (PKC), calcineurina e ATPases transmembranares de cálcio, importantes para a comunicação sináptica, são observadas em leveduras, que são unicelulares. ${ }^{71}$ Os coanoflagelados, grupo de protozoários filogeneticamente próximo do reino animal (Metazoa) também constituem modelo de comparação proteômica e genômica. Por exemplo, nesses protozoários são encontradas interações citoesqueléticas (envolvendo caderinas e actinas) ausentes em leveduras, mas essenciais para a formação de algumas sinapses em mamíferos e em Drosophila melanogaster. Isso sugere que tais proteínas citoesqueléticas teriam se desenvolvido originalmente nos pro- 


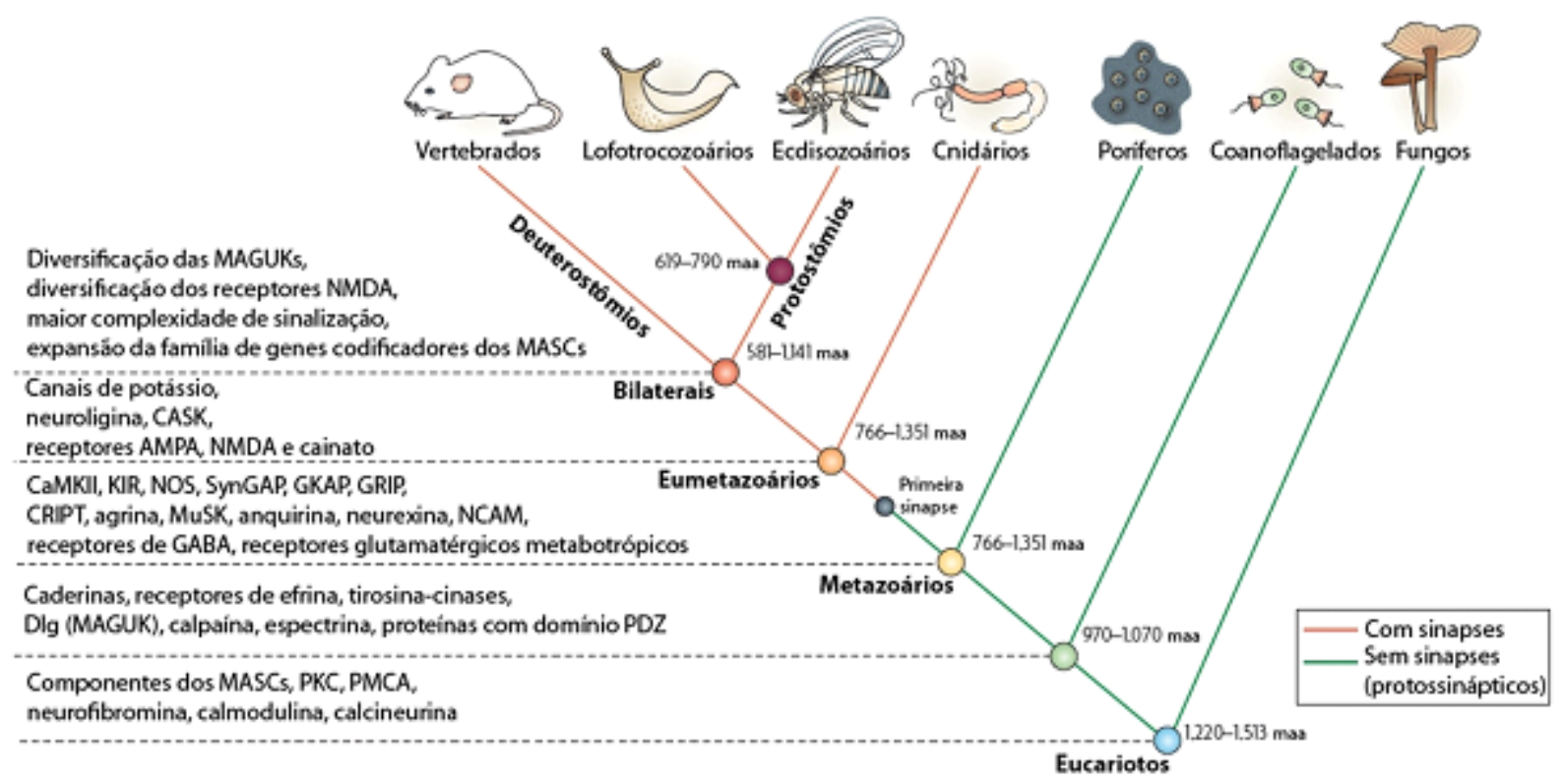

Figura 7: Cladograma (árvore filogenética) mostrando táxons relevantes para a evolução da sinapse. (adaptada e traduzida a partir da referência 70). Cada clado (ou grupo animal) é representado por desenhos de organismos-modelo no topo do cladograma. Os nós do cladograma, indicados por círculos coloridos, representam pontos de divergência entre os vários clados. Cada um destes nós é acompanhado pelo período de divergência estimado pela literatura em milhões de anos atrás (maa). Paralelamente à filogenia está uma série de proteínas exemplares envolvidas na formação e/ou funcionamento da sinapse, mostrando em quais intervalos da história evolutiva esses vários componentes protéicos das sinapses teriam surgido. AMPA: ?-amino-3-hydroxy-5-methyl-4-isoxazolepropionic acid; CaMKII: calcium/calmodulin-dependent protein kinase II; CASK: calcium/calmodulin dependent serine protein kinase; CRIPT: cysteinerich PDZ-binging protein; Dlg: discs, large homolog; GABA: ?-aminobutyric acid; GKAP: guanylate kinase associated protein; GRIP: glutamate receptor interacting protein; KIR: inwardly rectifying potassium channel; MAGUK: membrane-associated guanylate kinase; MASC: MAGUK-associated signalling complex; MuSK: muscle specific kinase; NCAM: neural cell adhesion molecule; NMDA: N-methyl-Daspartate; NOS: nitric oxide synthase; PKC: protein kinase C; PMCA: plasma membrane calcium transporting ATPase; SynGAP: synaptic Ras GTPase activating protein.

tozoários mais antigos. ${ }^{72,73}$ Ainda na categoria de organismos protossinápticos, os poríferos (esponjas) apresentam ainda maiores "novidades evolutivas", pois possuem, por exemplo, receptores GABAérgicos e mGluRs, que são ausentes em fungos e protozoários. Além disso, as células de poríferos possuem uma diversidade maior de interações entre proteínas intracelulares, que não é vista em leveduras e coanoflagelados. Portanto, embora careçam de um sistema nervoso, as esponjas possuem um conjunto razoável de proteínas protossinápticas. Isso indica que o ancestral comum das esponjas e do resto dos animais possivelmente possuía células com uma maquinaria biomolecular (importante para as respostas às contingências ambientais) que, mais tarde, teria sido cooptada para o estabelecimento da comunicação sináptica, como a conhecemos hoje. ${ }^{74}$

\section{Animais não-bilaterais com sistemas nervo- sos rudimentares}

Em cnidários (grupo que inclui as águas-vivas) são encontradas as sinapses mais básicas do reino animal e, provavelmente, as mais semelhantes às primeiras sinapses que surgiram no planeta. Diferentemente de fungos, protozoários e poríferos, os cnidários apresentam uma diversidade bem maior de receptores transmembrana, incluindo os iGluRs (AMPA, NMDA e cainato), que estão ausentes em poríferos. Porém, estes receptores interagem com proteínas intracelulares que já estavam presente nos poríferos, sugerindo que a existência de um arcabouço protéico intracelular na base de Metazoa teria alicerçado uma diversificação a posteriori de receptores transmembrana (muitos dos quais estão presentes nos sistemas nervosos de vertebrados). ${ }^{74}$ Portanto, em meio a essa diversificação de receptores, é curioso notar que os iGluRs seriam filogeneticamente mais recentes do que os mGluRs.

\section{Animais bilaterais}

Uma vez estabelecidos os primitivos sistemas nervosos reticulares, o grande grupo Bilateria, interno a Metazoa, desenvolveu simetria bilateral, acompanhada de crescente concentração de neurônios em um 
centro nervoso (cefalização). Paralelamente, os neurônios passaram a expressar, em suas sinapses, todos os receptores para neurotransmissores "clássicos" (colinérgicos, dopaminérgicos, serotoninérgicos, noradrenérgicos, etc.). Essa ideia é sustentada pelo fato de tanto protostômios quanto deuterostômios (dois principais grupos de Bilateria, diferenciados por critérios embriológicos) possuírem tais receptores. Além disso, quase $45 \%$ dos genes que codificam proteínas da PSD de camundongos encontra ortólogos (genes que evoluíram de forma divergente entre espécies, mas que possuem ancestral comum) na PSD de D. melanogaster. Ou seja, protostômios (como D. melanogaster) e deuterostômios (como roedores) compartilham um conjunto central de proteínas sinápticas homólogas, provavelmente tão antigas quanto os animais bilaterais mais primitivos da história filogenética. ${ }^{75,76}$

Contudo, as semelhanças entre protostômios e deuterostômios são limitadas, pois mais da metade dos genes que codificam certas famílias protéicas sinápticas em D. melanogaster tem ortólogos nas leveduras, enquanto isso ocorre com menos da metade das mesmas famílias protéicas sinápticas em camundongos. Assim, as sinapses de deuterostômios são enriquecidas com proteínas mais recentes filogeneticamente. Além disso, a PSD de deuterostômios, é muito mais diversificada do que a de protostômios, levando a novas combinações protéicas e aumentando a complexidade da sinalização sináptica. Em particular, os cordados (pertencentes ao grupo dos deuterostômios e que incluem os vertebrados) mostram diversificação ainda maior dos genes que codificam canais iônicos em geral, receptores glutamatérgicos e GABAérgicos, PKC, caderinas, proteína cinase II dependente de cálcio/calmodulinas (CaMKII), etc. ${ }^{71,74}$

Os receptores glutamatérgicos NMDA têm recebido especial atenção nas pesquisas sobre filogenia, dado o seu papel central nos mecanismos mais conhecidos de LTP e LTD. Comparando-se protostômios e deuterostômios há clara divergência entre os tamanhos dos NMDAs, mais especificamente em suas subunidades NR2. Em vertebrados, o domínio intracelular (com terminal carboxílico) dessa subunidade é cinco vezes maior do que em invertebrados. Como esses domínios intracelulares dos NMDA contêm sítios de fosforilação e interações protéicas que regulam a função do receptor, é provável que a gama de modulações sofridas por tais receptores em deuterostômios seja bem maior. ${ }^{77}$ No futuro, uma maior investigação sobre esse tema poderá trazer implicações interessantes sobre a evolução da plasticidade sináptica mediada por NMDA, que é subjacente a vários processos comportamentais de aprendizagem.

Quanto ao sistema nervoso humano, a investigação proteômica das sinapses sob ponto de vista evolutivo é uma abordagem recente que ainda demanda progressos. Mesmo assim, existem dados sugerindo uma seleção positiva (evolução acelerada) atuando sobre receptores colinérgicos, dopaminérgicos, glutamatérgicos, etc. Essa evolução acelerada estaria levando a um enriquecimento sem precedentes da maquinaria biomolecular das sinapses, o que pode estar na base de uma vulnerabilidade aumentada do encéfalo humano a doenças neurológicas. ${ }^{78-80}$

\begin{abstract}
Communication between neurons is subject to constant changes, even in the adult brain. This ability of neural circuits to strengthen or weaken their specific synaptic interactions (a phenomenon known as synaptic plasticity) may occur according to different environmental demands, which favors the idea that dynamic changes in the communication between neurons underlie behavioral flexibility (i.e., learning and memory processes). In recent decades, advances in neuroscience has allowed a better understanding of synaptic plasticity, specially the plasticity of glutamatergic synapses, whose molecular processes of synaptic change appear to be among the most common throughout the central nervous system. Much of this progress in basic science has contributed to a better understanding of pathological processes involving the glutamatergic synapses, such as Alzheimer's disease. Furthermore, the growing understanding about the physiology of glutamatergic communication has helped explain how synapses, in general, would have originated and evolved in the phylogenetic scale of the Metazoa. This review attempts to address clinical aspects of glutamatergic neurotransmission, contextualizing such aspects with basic knowledge about synaptic plasticity and evolution of synapses.
\end{abstract}

Keywords: Glutamate. Excitotoxicity. N-Methyl-D-Aspartate. Synaptic Plasticity. Neuroprotection. 


\section{Referências}

1. Mattson MP, Bruce-Keller AJ. Compartmentalization of signaling in neurons: evolution and deployment. J Neurosci Res. 1999; 58: 2-9.

2. Purves D, Augustine GJ, Fitzpatrick D, Hall WC, LaMantia AS, McNamara JO, Williams SM. Neuroscience. 3rd ed. Sunderland, Massachusetts (USA): Sinauer Associates Inc. Publishers; 2004.

3. Bittigau P, Ikonomidou C. Glutamate in neurologic diseases. J Child Neurol. 1997; 12: 471-85.

4. Prybylowski K, Wenthold RJ. N-Methyl-D-aspartate receptors: subunit assembly and trafficking to the synapse. J Biol Chem. 2004; 279: 9673-6.

5. Bowie D. Ionotropic Glutamate Receptors and CNS disorders. CNS Neurol Disord Drug Targets. 2008; 7: 129-43.

6. Pinheiro OS, Mulle Christophe. Presynaptic glutamate receptors: physiological functions and mechanisms of action. Nat Rev Neurosci. 2008; 9: 423-36.

7. Lucas DR, Newhouse JP. The toxic effect of sodium L-glutamate on the inner layers of the retina. Arch Ophtalmol 1957; 58: 193-201.

8. Olney JW. Neurotoxicity of excitatory amino acids. In: McGeer EG, Olney JW, McGeer PL, eds; Kainic acid as a tool in neurobiology. New York: Raven Press; 1978. p. 95-121.

9. Olney JW. Brain lesion, obesity and other disturbances in mice treated with monosodium glutamate, Science 1969; 164: 719-21.

10. McBain CJ, Mayer ML. N-methyl-D-aspartic acid receptor structure and function. Physiol Ver 1994; 74: 723-60.

11. Kubo M, Ito E. Structural dynamics of an ionotropic glutamate receptor. Proteins 2004; 56: 411-9.

12. Orrenius S, Ankarcrona M, Nicotera P. Mechanisms of calciumrelated cell death. Adv Neurol 1996; 71: 137-51.

13. Sattler R, Tymianski M. Molecular mechanisms of calcium-dependent excitotoxicity. J Mol Med 2000; 78: 3-13.

14. Arundine M, Tymiansky M. Molecular mechanisms of calciumdependent neurodegeneration in excitotoxicity. Cell Calcium 2003; 34: 325-37.

15. Beal MF. Mechanisms of excitotoxicity in neurologic diseases. FASEB J 1992; 6: 3338-44.

16. Moussa CEH, Rae C, Bubb WA, Griffin JL. Inhibitors of glutamate transport modulate distinct patterns in brain metabolism. J Neurosci Res. 2007; 85: 342-50.

17. Citri A, Malenka RC. Synaptic plasticity: multiple forms, functions, and mechanisms. Neuropsychopharmacology Rev 2008; 33: 18-41.

18. Zucker RS, Regehr WG. Short-term synaptic plasticity. Annu Rev Physiol 2002; 64: 355-405.

19. Bliss TV, Lomo T. Long-lasting potentiation of synaptic transmission in the dentate area of the anaesthetized rabbit following stimulation of the perforant path. J Physiol 1973; 232: 331-56

20. Nicoll RA, Kauer JA, Malenka RC. The current excitement in long-term potentiation. Neuron 1988; 1: 97-103.

21. Barria A, Muller D, Derkach V, Griffith LC, Soderling TR. Regulatory phosphorylation of AMPA-type glutamate receptorsby CaMKII during long-term potentiation. Science 1997; 276: 2042-5.

22. Malenka RC, Kauer JA, Perkel DJ, Mauk MD, Kelly PT, Nicoll RA, et al. An essential role for postsynaptic calmodulin and protein kinase activity in long-term potentiation. Nature 1989; 340: 554-7.
23. Lledo PM, Hjelmstad GO, Mukherji S, Soderling TR, Malenka RC Nicoll RA. Calcium/calmodulin-dependent kinase II and longterm potentiation enhance synaptic transmission by the same mechanism. Proc Natl Acad Sci USA 1995; 92: 11175-9.

24. Blitzer RD, Connor JH, Brown GP, Wong T, Shenolikar S, lyengar R, et al. Gating of CaMKII by cAMP-regulated protein phosphatase activity during LTP. Science 1998; 280: 1940-2.

25. Serrano P, Yao Y, Sacktor TC. Persistent phosphorylation by protein kinase Mzeta maintains late-phase long-term potentiation. J Neurosci 2005; 25: 1979-84.

26. Sweatt JD. Mitogen-activated protein kinases in synaptic plasticity and memory. Curr Opin Neurobiol 2004; 14: 311-7.

27. Derkach VA, Oh MC, Guire ES, Soderling TR. Regulatory mechanisms of AMPA receptors in synaptic plasticity. Nat Ver Neurosci 2007; 8: 101-13.

28. Malenka RC, Nicoll RA. Silent synapses speak up. Neuron 1997; 19: 473-6.

29. Zhou Y, Wu H, Li S, Chen Q, Cheng XW, Zheng J, et al. Requirement of TORC1 for late-phase long-term potentiation in the hippocampus. PLoS ONE 2006; 1: E16.

30. Thomas GM, Huganir RL. MAPK cascade signalling and synaptic plasticity. Nat Rev Neurosci. 2004; 5: 173-83.

31. Lamprechet R, LeDoux J. Structural plasticity and memory. Nat Rev Neurosci. 2004; 5: 45-54.

32. Dudek SM, Bear MF. Homosynaptic long-term depression in area CA1 of hippocampus and effects of N-methyl-D-aspartate receptor blockade. Proc Natl Acad Sci USA 1992; 89: 4363-7.

33. Cummings JA, Mulkey RM, Nicoll RA, Malenka RC. $\mathrm{Ca}^{2+}$ signaling requirements for long-term depression in the hippocampus. Neuron 1996; 16: 825-33.

34. Morishita W, Connor JH, Xia H, Quinlan EM, Shenolikar S, Malenka RC. Regulation of synaptic strength by protein phosphatase 1. Neuron 2001; 32: 1133-48.

35. Lee HK, Barbarosie M, Kameyama K, Bear MF, Huganir RL. Regulation of distinct AMPA receptor phosphorylation sites during bidirectional synaptic plasticity. Nature 2000; 405: 955-9.

36. Banke TG, Bowie D, Lee H, Huganir RL, Schousboe A, Traynelis SF. Control of GluR1 AMPA receptor function by cAMPdependent protein kinase. J Neurosci 2000; 20: 89-102.

37. Carroll RC, Beattie EC, Xia H, Luscher C, Altschuler Y, Nicoll RA, et al. Dynamin-dependent endocytosis of ionotropic glutamate receptors. Proc Natl Acad Sci USA 1999; 96: 14112-7.

38. Beattie EC, Carroll RC, Yu X, Morishita W, Yasuda H, von Zastrow M, et al. Regulation of AMPA receptor endocytosis by a signaling mechanism shared with LTD. Nat Neurosci 2000; 3: $1291-300$

39. Carroll RC, Beattie EC, von Zastrow M, Malenka RC. Role of AMPA receptor endocytosis in synaptic plasticity. Nat Rev Neurosci. 2001; 2: 315-24.

40. Zhou Q, Homma KJ, Poo MM. Shrinkage of dendritic spines associated with long-term depression of hippocampal synapses. Neuron 2004; 44: 749-57.

41. Takumi $Y$, Ramirez-Leon V, Laake P, Rinvik E, Ottersen OP. Different modes of expression of AMPA and NMDA receptors in hippocampal synapses. Nat Neurosci 1999; 2: 618-24.

42. Tsien JZ, Huerta PT, Tonegawa S. The essential role of hippocampal CA1 NMDA receptor-dependent synaptic plasticity in spatial memory. Cell 1996; 87: 1327-38.

43. Tang YP, Shimizu E, Dube GR, Rampon C, Kerchner GA, Zhuo $M$, et al. Genetic enhancement of learning and memory in mice. Nature 1999; 401: 63-9 
44. Whitlock JR, Heynen AJ, Shuler MG, Bear MF. Learning induces long-term potentiation in the hippocampus. Science 2006; 313: 1093-7.

45. Yao Y, Kelly MT, Sjikumar S, Serrano P, Tian D, Bergold PJ, et al. $\mathrm{PKM}$ ? maintains late long-term potentiation by $\mathrm{N}$-ethylmaleimidesensitive factor/GluR2 dependent trafficking of postsynaptic AMPA receptors. J Neurosci 2008; 28: 7820-7

46. Tsvetkov E, Carlezon WA, Benes FM, Kandel ER, Bolshakov VY. Fear conditioning occludes LTP-induced presynaptic enhancement of synaptic transmission in the cortical pathway to the lateral amygdala. Neuron 2002; 34: 289-300.

47. Rumpel S, LeDoux J, Zador A, Malinow R. Postsynaptic receptor trafficking underlying a form of associative learning. Science 2005; 308: 83-8.

48. Walker DL, Ressler KJ, Lu KT, Davis M. Facilitation of conditioned fear extinction by systemic administration or intra-amygdala infusions of D-cycloserine as assessed with fearpotentiated startle in rats. J Neurosci 2002; 22: 2343-51

49. Faleiro LJ, Jones S, Kauer JA. Rapid synaptic plasticity of glutamatergic synapses on dopamine neurons in the ventral tegmental area in response to acute amphetamine injection. Neuropsychopharmacology 2004; 29: 2115-25.

50. Saal D, Dong Y, Bonci A, Malenka RC. Drugs of abuse and stress trigger a common synaptic adaptation in dopamine neurons. Neuron 2003; 37: 577-82.

51. Foeller E, Feldman DE. Synaptic basis for developmental plasticity in somatosensory cortex. Curr Opin Neurobiol 2004; 14 : 89-95.

52. Karmarkar UR, Dan Y. Experience-dependent plasticity in adult visual cortex. Neuron 2006; 52: 577-85.

53. Kreitzer AC, Malenka RC. Endocannabinoid-mediated rescue of striatal LTD and motor deficits in Parkinson's disease models. Nature 2007; 445: 643-7.

54. Lopes Aguiar C, Romcy-Pereira RN, Szawka RE, Galvis-Alonso OY, Anselmo-Franci JA, Pereira JP. Muscarinic acetylcholine neurotransmission enhances the late-phase of long-term potentiation in the hippocampal-prefrontal cortex pathway of rats in vivo: a possible involvement of monoaminergic systems. Neuroscience 2008; 153: 1309-19.

55. Kawamata M, Omote K. Involvement of increased excitatory amino acids and intracellular $\mathrm{Ca}^{2+}$ concentration in the spinal dorsal horn in an animal model of neuropathic pain. Pain 1996; 68: 85-96.

56. Choi DW. Calcium: still center-stage in hypoxic-ischemic neuronal death. Trends Neurosci 1995; 18: 58-60.

57. Choi DW. Calcium-mediated neurotoxicity: relationship to specific channel types and role in ischemic damage. Trends Neurosci 1988; 11: 465-9.

58. Weille JR, Schweitz H, Maes P, Tartar A, Lazdunski M. Calciseptine, a peptide isolated from black mamba venom, is a specific blocker of the L-type calcium channel, Proc Natl Acad Sci USA 1991; 88: 2437-40.

59. Simon RP, Swan JH, Meldrum BS. Blockade of N-methyl-Daspartate receptors may protect against ischemic damage in the brain. Science 1984; 226: 850-2.

60. Ozyurt E, Graham DI, Woodruff GN, McCulloch J. Protective effect of the glutamate antagonist MK-801 in focal cerebral ischemia in the cat, J. Cereb. Blood Flow Metab 1988; 8: 13843.

61. Lees KR. Does neuroprotection improve stroke outcome? Lancet 1998; 351: 1447-8.
62. Olney JW, Ikonomidou C, Mosinger JL, Frierdich G. MK-801 prevents hypobaric ischemic neuronal degeneration in infant rat brain. J Neurosci 1989, 9: 1701-4.

63. Fix AS, Horn JW, Wightman KA, Johnson CA, Long GG, Storts $R W$, et al. Neuronal vacuolization and necrosis induced by the noncompetitive $\mathrm{N}$-methyl-D-aspartate (NMDA) antagonist $\mathrm{MK}(+) 801$ (dizocilpine maleate): a light and electron microscopic evaluation of the rat retrosplenial cortex. Exp Neurol 1993; 123: 204-15.

64. Corso TD, Sesma MA, Tenkova TI, Der TC, Wozniak DF, Farber NB et al. Multifocal brain damage induced by phencyclidine is augmented by pilocarpine. Brain Res 1997; 752: 1-14.

65. Lipton SA. Paradigm shift in NMDA receptor antagonist drug development: molecular mechanism of uncompetitive inhibition by memantine in the treatment of Alzheimer's disease and other neurologic disorders. J Alzheimers Dis 2004; 6: S61-74.

66. Hirbec H, Gaviria M, Vignon J. Gacyclidine: a new neuroprotective agent acting at the $\mathrm{N}$-methyl-D-aspartate receptor. CNS Drug Rev 2001; 7: 172-98.

67. Lepeintre JF, D'Arbigny P, Mathé JF, Vigué B, Loubert G, Delcour J. Neuroprotective effect of gacyclidine. A multicenter doubleblind pilot trial in patients with acute traumatic brain injury. Neurochirurgie 2004; 50: 83-95.

68. Krause T, Gerbershagen MU, Fiege M, Weisshorn R, Wappler F. Dantrolene: a review of its pharmacology, therapeutic use and new developments. Anaesthesia 2004; 59: 364-73.

69. Kawaguchi, M., Furuya, H., Patel, PM. Neuroprotective effects of anesthetic agents. J Anesth 2005; 19: 150-6.

70. Ryan TJ, Grant SGN. The origin and evolution of synapses. Nature Rev Neurosci 2009; 10: 701-12.

71. Emes RD, et al. Evolutionary expansion and anatomical specialization of synapse proteome complexity. Nature Neurosci 2008; 11: 799-806.

72. King N, Hittinger CT, Carroll SB. Evolution of key cell signaling and adhesion protein families predates animal origins. Science 2003; 301: 361-3.

73. Pincus D, Letunic I, Bork P, Lim WA. Evolution of the phosphortyrosine signaling machinery in premetazoan lineages. Proc Natl Acad Sci USA 2008; 105: 9680-4.

74. Sakarya O, Armstrong KA, Adamska M, Adamski M, Wang IF, Tidor B, et al. A post-synaptic scaffold at the origin of the animal kingdom. PLoS One 2007; 2: e506.

75. Walker RJ, Brooks HL, Holden-Dye L. Evolution and overview of classical transmitter molecules and their receptors. Parasitology 1996; 113: S3-S33.

76. Littleton JT, Ganetzky B. Ion channels and synaptic organization: analysis of the Drosophila genome. Neuron 2000; 26 : 3543.

77. Sprengel R, Suchanek B, Amico C, Brusa R, Burnashev N, Rozov A, et al. Importance of the intracellular domain of NR2 subunits for NMDA receptor function in vivo. Cell 1998; 92 : 279-89.

78. Dorus S, et al. Accelerated evolution of nervous system genes in the origin of Homo sapiens. Cell 2004; 119: 1027-40.

79. Crow TJ. The "big bang" theory of the origin of psychosis and the faculty of language. Schizophr Res 2008; 102: 31-52.

80. Pearlson GD, Folley BS. Schizophrenia, psychiatric genetics, and Darwinian psychiatry: an evolutionary framework. Schizophr Bull 2008; 34: 722-33. 